\title{
Actin Filament
}

National Cancer Institute

\section{Source}

National Cancer Institute. Actin Filament. NCI Thesaurus. Code C13255.

The finest filamentous element of the cytoskeleton, having a diameter of about $5 \mathrm{~nm}$ and consisting primarily of actin. 